\title{
Systematic value of the ultrastructure of the sucker surface in the squid family Mastigoteuthidae (Mollusca: Cephalopoda)
}

\author{
Mario Alejandro Salcedo-Vargas \\ Institute for Systematics and Population Biology, University of Amsterdam, P.O. Box 94766, \\ 1090 GT Amsterdam, The Netherlands*
}

Keywords: Cephalopoda, Mastigoteuthidae, systematics, Northwest Pacific, „suckers, ultrastructure

\begin{abstract}
The ultrastructure of the sucker surface is described and its systematic value for mastigoteuthid squids, which bear minute suckers, is considered. An introduction to sucker terms is given and a redefinition of these terms is attempted. Using scanning electron microscopic data, two genera and four subgenera of Mastigoteuthidae from the Northwest Pacific are distinguished. The presence of "cushions" in the sucker is discussed and considered as a character important for understanding adaptations of cephalopods to the deep-sea.
\end{abstract}

\section{Résumé}

L'ultrastructure de la surface des minuscules ventouses des Céphalopodes de la famille des Mastigoteuthidae est décrite, sa valeur pour leur systématique étant discutée. Est proposée une introduction à la terminologie des ventouses et un essai de rédéfinition de celle-ci est fâit. L'utilisation des données obtenues à l'aide du microscope électronique à balayage permet de distinguer dans le Pacifique du N.O. deux genres et quatre sous-genres de Mastigoteuthidae. La présence de "coussinets" dans les ventouses est discutée, et considérée comme caractère important pour comprendre les adaptations des Céphalopodes à la vie dans les mers profondes.

\section{Introduction}

Suckers are an important taxonomic character at familial, generic, and specific levels. The study and use of suckers for classification was initiated by Naef $(1921 / 23)$. Studies on the use of suckers in feeding brought Nixon \& Dilly (1977) to the conclusion that some of the sucker components defined as pegs are involved in the mechanics of intimate contact. They also proved that the growth of the sucker infundibulum takes place at the periphery.

Nixon \& Dilly (1977) postulated that the differences in diameter, size, and shape of sucker components in 10 cephalopod species depend on physiology and behaviour. Nevertheless, the morphology of the surface of the sucker, its components and its variations, chiefly in regard to minute suckers, have been ignored both as a taxonomic character and for systematic purposes.

Studies of the suckers in Mastigoteuthidae have been carried out by Chun (1910), Young (1972), Nixon \& Dilly (1977), and Dilly et al. (1977), who focused their attention on the chitinous ring morphology. A study of the ultrastructure of suckers, using $\mathbf{3 1 0}$ mastigoteuthid specimens in the collection of the Tokyo University of Fisheries, has been made in order to evaluate the systematic value of the pegs and other sucker components, useful to distinguish not only genera but also subgenera and even species (Salcedo-Vargas, 1993). During this study, detailed observations of the morphology of suckers were carried out using the scanning electron microscope (SEM). This extensive and detailed research, which includes additional reference material from the North Atlantic (loaned specimens, foreign collections, and unpublished material), as well as a total of 250 micrographs, provides the

- Present address: Saginomiya Squid Research Laboratory (SSRL), 2F-2-4-11 Kami-Saginomiya, Nakano-ku, Tokyo 165, Japan. 
basis for the synthesis presented in this contribution. Classification changes in the family Mastigoteuthidae, based partially on sucker morphology, are published in a separate paper (Salcedo-Vargas \& Okutani, 1994) in which the family is divided in two genera, each with two subgenera.

In the present paper, three aspects of suckers are considered: (1) an attempt at a revision of sucker terminology; (2) a description of the morphological ultrastructure of the tentacular and arm suckers for the taxa studied; and (3) a re-evaluation of the sucker formations, here called "cushions", and of the sucker surface, and their respective systematic value in the family Mastigoteuthidae.

\section{Materials and methods}

The $\mathbf{3 1 0}$ specimens examined are all from the Northwest Pacific and are deposited in the collection of the Laboratory of Invertebrates of the Tokyo University of Fisheries. The appearance of each of the subgenera defined can be observed in SalcedoVargas \& Okutani (1994).

A JEOL JSM-T20 scanning electronic microscope (SEM) was used for observations of the ultrastructure. The samples selected were washed with distilled water and placed in the ultrasonic cleaner AUC-201 from 1 to 3 seconds. Dehydration with different concentrations of alcohol, changing the sample every hour from $65,70,80,90,95 \%$ and absolute, and later transferring into 3-metylbutyl acetate, made the sample ready for freeze drying. The samples were mounted on stubs and gold-coated in the ion sputter JFC-1100.

\section{Sucker gross terminology}

The terminology of suckers as defined by Naef (1921/1923) and updated by Nixon \& Dilly (1977) is used. Standardization and redefinition of some terms for the components of the suckers is given here. The updated and newly introduced terms are illustrated and explained in detail. Line drawings of the re-evaluated terminology are presented in Fig. 1.

\section{Sucker}

This is the cup-like, globular or helmet-shaped structure that is located mostly on oral surfaces of the arms and tentacles (and on the buccal mem- brane of a few species). Depending on the taxonomic group, the sucker may develop relatively muscular structures. A chitinous ring which varies in shape, consistency, thickness, length, width, depth and diameter, occurs at its opening. This ring consists of horny material, and usually develops denticles that are highly variable in shape and number. Ontogenetic modifications of suckers into hooks and "cushions" (defined here), and probably other structures are present in some groups. The soft rings of octopod suckers do not develop horny rings or denticles, but develop soft cushioned rings.

\section{Sucker surface}

This is the area in which the main components (acetabulum, infundibular ring, and papillated ring) are located. This surface varies in diameter according to the size of the sucker, its position in the arm and tentacular club, the taxa concerned, and the size of the specimen.

\section{Cushion}

This is the single or multiple globular soft structure that grows out from the internal walls of the infundibular ring, chamber, veil, or the teeth in the arm and tentacular suckers, particularly in some mesobathypelagic squids. It has also been called hump and lump (Chun, 1910; Sasaki, 1929). In hookbearing taxa, the presence of a horny-type of cushion has been observed.

\section{Terminology of sucker (sub)components}

(Fig. 1)

Suckers have three main components (Fig. 1a, c). These are: (1) the acetabulum, (2) the infundibular ring, and (3) the papillated ring. Currently used terms are discussed and newly introduced terms are indicated in Table I. The sucker components consist of subcomponents that are defined as follows: 
Table I. Sucker components and their names.

\begin{tabular}{cccc}
\hline Components & 1st & 2nd & 3rd \\
& Acetabulum & Infundibular ring & Papillated ring
\end{tabular}

Subcomponents

\begin{tabular}{llc} 
Stalk & Teeth & Polygonal \\
Sucker pad & $\begin{array}{l}\text { Veil } \\
\text { Infundibular } \\
\text { chamber }\end{array}$ & process \\
& Pegs \\
& Rim \\
\hline
\end{tabular}

1st Component: acetabulum; subcomponents: stalk and sucker pad

The first component of the suckers in cephalopods is the acetabulum, which is the primary structure upon which the others depend, and which contains the main avity of the sucker. The acetabulum is a soft chamber composed of translucent or transparent tissue, and is globular, cup- or helmet-shaped. It is attached directly to the oral surface of the arm which is supported by a stalk that can vary in architecture, length and thickness. The sucker pad is also observed in some groups (Fig. 1c).

The size and architecture of the opening of the acetabulum varies depending on the taxonomic group. In decapods it is usually moderate to wide; in octopods it is generally narrow in comparison to the squid sucker surface.

2nd Component: infundibular ring (= horny ring, inner ring, chitinous ring); subcomponents: teeth, veil, and infundibular chamber

The second component is the infundibular ring, formerly known as the horny ring, inner ring or chitinous ring. It is located on the sucker opening, which is called here the infundibulum, and it generally bears several types of protrusions, called teeth or denticles.

The infundibular ring can be toothless, "smooth", or have many teeth. The shape of the teeth varies from group to group, but the most common shapes are wedge-like, conical, slightly or clearly sharpened, short-rectangular, rounded, or blunt. In some taxa, there is a combination of two or more kinds of teeth.

Nomenclature. - The infundibular ring is usually analyzed in two modes: extracted from the infundibulum or embedded in it. In enlarged suckers, it is normally attached just inside the infundibulum, and it can be extracted easily by removing the papillated ring (see third component). On the other hand, in small suckers this ring is fragile and deeply embedded in the acetabulum, and not easily extracted. Therefore, in its analysis the whole sucker surface is examined.

This meant the ring was given two names. When it is extracted from the acetabulum it was called the horny ring. The second term used was the inner ring, for when it is analyzed embedded in the acetabulum.

Nixon \& Dilly (1977) originally proposed the term infundibulum to indicate the sucker opening as well as the ring, and were supported by Haas (1989). Therefore, in order to standardize the terminology, another term can be used, viz., infundibular ring. Thus, all kinds of toothed or smooth sucker rings, extracted or not, may be called infundibular rings.

In arm suckers, an accessorial subcomponent has developed from the internal side of the infundibular ring into the cavity of the acetabulum. This structure is here defined as the veil, which varies in size and shape from proximal to distal margin and gives support to the infundibular ring. The veil is normally overlooked in enlarged suckers because it is narrow and attention is usually given to the teeth. In groups with small suckers, the veil is wide and deeply embedded in the acetabulum (Fig. 1c).

The morphology of the veil and the infundibular ring in some tentacular suckers of deep-sea decapods and some sepiolid species differs slightly from the standard morphology. In some cases, the sucker opening narrows abruptly, forming a neck in which the infundibular ring is set, with an opening at the distal or lateral side. In others, the tissue of the acetabulum is reduced and the infundibular ring develops an even wider veil. The weaker the covering tissue, the more developed the veil, and vice versa. Thus, for small tentacular suckers, the tissue cor- 
responding to the acetabulum is extremely reduced to a very thin and transparent membrane, and the veil turns into a complete infundibular (chitinous) chamber.

In the case of suckers which have modified into hooks and those that develop cushions, the infundibular ring is also modified. In these specific sucker types (hooked or cushioned), a chamber of horny material has developed inside the acetabulum and from the infundibular ring, for which the term infundibular chamber is proposed. This term can be used for the small tentacular suckers and for modified suckers (Fig. 1d).

3rd Component: papillated ring (= outer ring; papillated area); subcomponents: polygonal processes (internal, intermediate, and external ring), pegs (adjacent denticles), and rim

The third component, here called the papillated ring, is referred to as the "outer ring" by Nixon \& Dilly (1977) and Haas (1989). It is located on the periphery of the infundibulum and is in close contact with the infundibular ring. The papillated ring consists of a series of three to eight independent rings, the number depending on the group and the ontogenetic stage. Each ring is formed by structural units which were defined as the polygonal processes by Nixon \& Dilly (1977). Every polygonal process is in close contact with the others. The three subrings of the papillated ring can be named as follows: the one in contact with the infundibular ring can be called the internal ring; the one between the subrings the intermediate ring; and the one in contact with the rim the external ring (Figs. 1a, b).

In the center of each polygonal process a peg protrudes. Its shape and size varies in every sub-ring, but it can still be useful for identifying taxa and growing stage. The term peg was introduced by Nixon \& Dilly (1977). There are some enlarged pegs in the distal margin of the internal ring of some taxa, and those pegs are defined here as adjacent denticles (Fig. 3). The pegs can be globular, dropor stalactite-like. For details about their formation, see Nixon \& Dilly (1977) and Haas (1989).
The last component is the rim, which is in contact with the external sub-ring of the papillated ring. The rim is morphologically like the polygonal processes and is usually overlooked in decapod suckers. In contrast, in octopod suckers the cushioned rim is so large that it constitutes the main component of the sucker surface, in which case the papillated ring is poorly developed and is located on the internal wall of the acetabulum cavity (Fig. 1f).

Nomenclature. - As with the infundibular ring, a variety of terms have been used (Table II). This component was called the "outer ring" when it was an unmodified ring, i.e., with flat and small polygonal processes. It was called the "papillated area" when referring to it independently as a structure or when the pegs were conspicuous or modified in the distal margin.

Table II. Names suggested by other authors for the papillated ring and its subcomponents.

\begin{tabular}{ll}
\hline Author & Nomenclature \\
\hline Nixon \& Dilly (1977) & $\begin{array}{l}\text { Cuticular surface } \\
\text { Infundibular cuticle }\end{array}$ \\
Kristensen (1977) & $\begin{array}{l}\text { (distal) Chitinous papillae } \\
\text { (proximal) Attachment ring } \\
\text { (rim) Chitinous rib }\end{array}$ \\
Haas (1989) & $\begin{array}{l}\text { Polygonal platelets } \\
\text { Horny coverings }\end{array}$ \\
Cephalopod literature in & Outer ring \\
general & Papillated area \\
\hline
\end{tabular}

\section{Results}

\section{Ultrastructure of arm suckers}

The suckers (= whole structure) of Mastigoteuthidae are aligned in two rows along the arms. Morphologically they are clearly divisible into two main types: (1) small, elongate and strongly dentated; (2) large, globular, and with nearly smooth infundibular rings. 

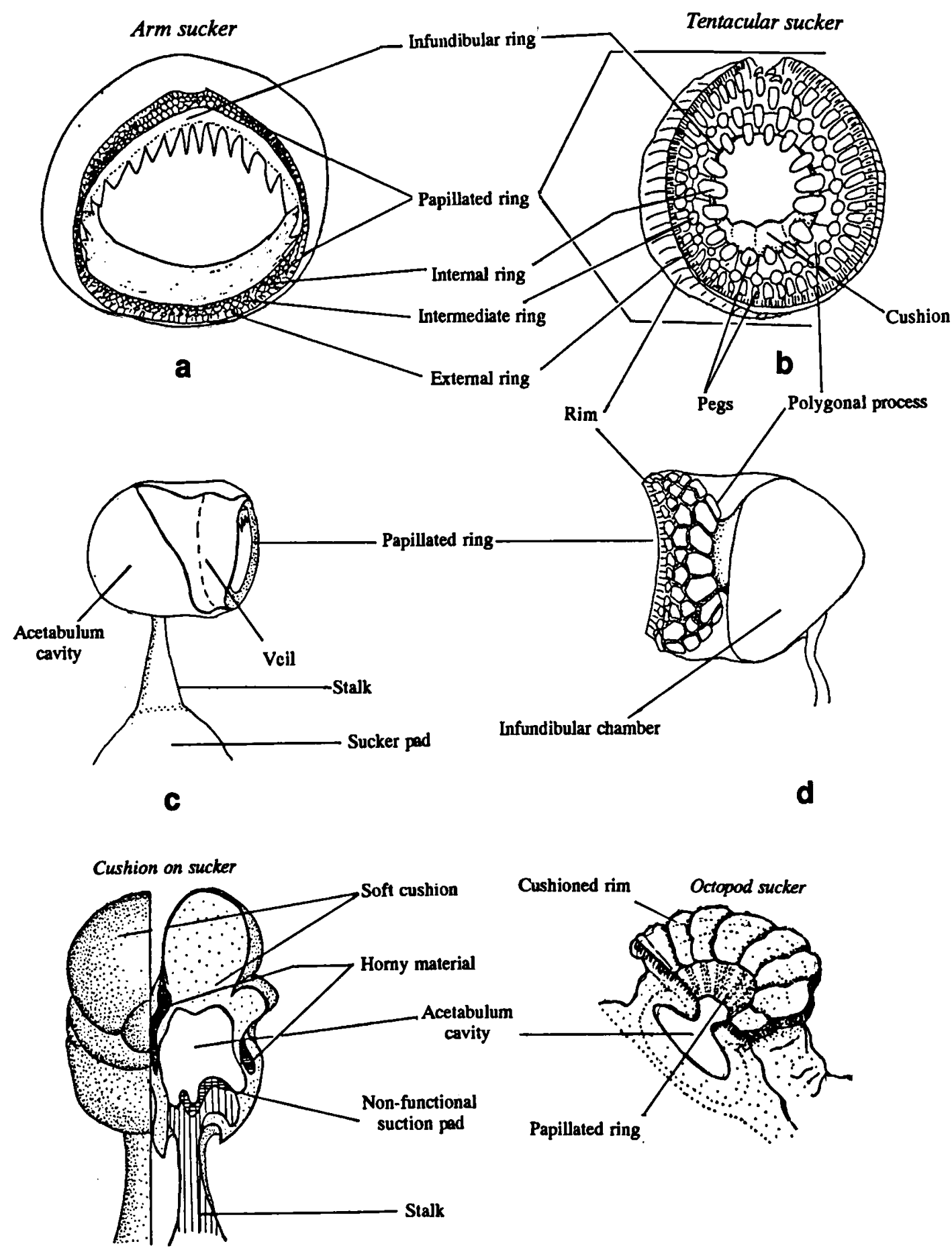

Fig. 1. Sucker components and subcomponents terminology: a, surface of arm sucker; b, surface of tentacular sucker; c, arm sucker, lateral view; d, tentacular sucker, lateral view; e, cushioned sucker, cross section; $f$, example of octopod sucker, cross section. 
Arm sucker type 1

(Figs. 2-3)

This type of sucker typically has papillated rings with three rings of polygonal processes with pegs projecting from the surface. Their shapes and forms vary with their position on the infundibulum (Nixon \& Dilly, 1977). The size, shape and number of polygonal rings also vary depending on the size of the specimen and the position of the sucker on the arm.

Acetabulum. - The outline is elongate, helmetshaped, and its opening is moderate in large specimens (mantle length [ML] > $90 \mathrm{~mm}$ ). The stalk, which is based on a small and blunt sucker pad, is thin and short.

Infundibular ring. - The number of teeth ranges from 6 in specimens smaller than $50 \mathrm{~mm}$ ML to 18 in mature specimens of $150 \mathrm{~mm} \mathrm{ML}$. The teeth are distributed along the distal margin and are conically sharp in its center, gradually becoming wider and blunter toward the proximal margin where the surface is nearly smooth (Fig. 2). The veil is large, especially in suckers from the middle to the proximal part of the arm.

Papillated ring. - The size and width of the pegs change from the internal to external ring. In the internal ring at the distal margin, the pegs are slender and tall, and in the proximal margin they are much stouter, occupying a larger portion of the base of the process (Nixon \& Dilly, 1977). The pegs at the distal margin of the intermediate and external rings are reduced in height, but wider than the ones of the internal ring. At the proximal margin the pegs are reduced in size, hence some sucker surfaces are completely flat. Slender, elongated and flat processes border the sucker surface in the periphery (Fig. 3).

The adjacent denticles (modified pegs in the distal margin) point toward the periphery, and their proximal face is curved and taller than that of the proximal margin, which barely rises above the level of the base (Fig. 3). The adjacent denticles are present in almost all suckers in small specimens
( $\leq 50 \mathrm{~mm} \mathrm{ML}$ ), but in larger ones (>100 $\mathrm{mm} \mathrm{ML)}$ they are observed mainly in the distal suckers.

Remarks. - This kind of sucker occurs in the genus Mastigoteuthis. In M. agassizi (Verrill, 1881) the adjacent denticles are more conspicuous than in $\boldsymbol{M}$. famelica Berry, 1913, or M. glaukopis Chun, 1910, which bear fewer and blunter teeth.

\section{Arm sucker type 2}

(Figs. 4-7)

The second type of sucker is larger, globular, sometimes enlarged in the middle part of the arm, with weakly dentated or smooth rings. The architecture of the sucker surface in this type is more uniform than in the first type of sucker discussed.

Acetabulum. - The outline is globular, its opening is large in both small and large specimens. The suckers are enlarged in arm III. The stalk is moderately thick and short, projecting from a blunted sucker pad.

Infundibular ring. - The teeth in small specimens ( $<100 \mathrm{~mm} \mathrm{ML)}$ are visible in all suckers. Their number ranges from 4 to 16 . In large specimens (> $150 \mathrm{~mm} \mathrm{ML}$ ), the infundibular ring gradually becomes smooth or with swollen areas, especially in proximal suckers (Fig. 4). The teeth are rounded or blunt (Fig. 5). The veil is moderate to large.

Papillated ring. - The sucker surface consists of three to seven rings of flat polygonal processes in Idioteuthis magna (Joubin, 1913) (Figs. 4, 5). In I. cordiformis (Chun, 1908), the polygonal processes are rounded and slightly globular (Figs. 6, 7). The size and width of the polygonal processes change from the internal to the external ring. The pegs of intermediate and external rings at the distal margin are reduced in size, but there is no significant difference among the rings of polygonal processes, which are completely flat (Fig. 7).

Remarks. - This type of sucker occurs in the genus Idioteuthis (Figs. 4-6). It is observed that sucker 
2

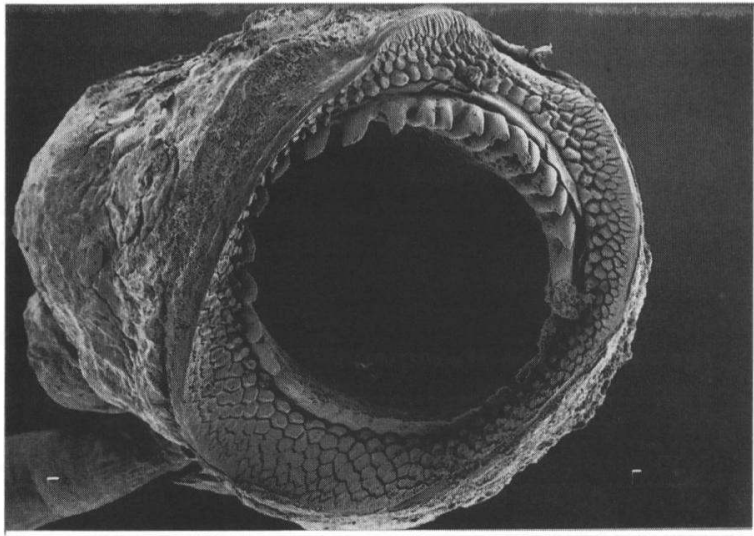

4
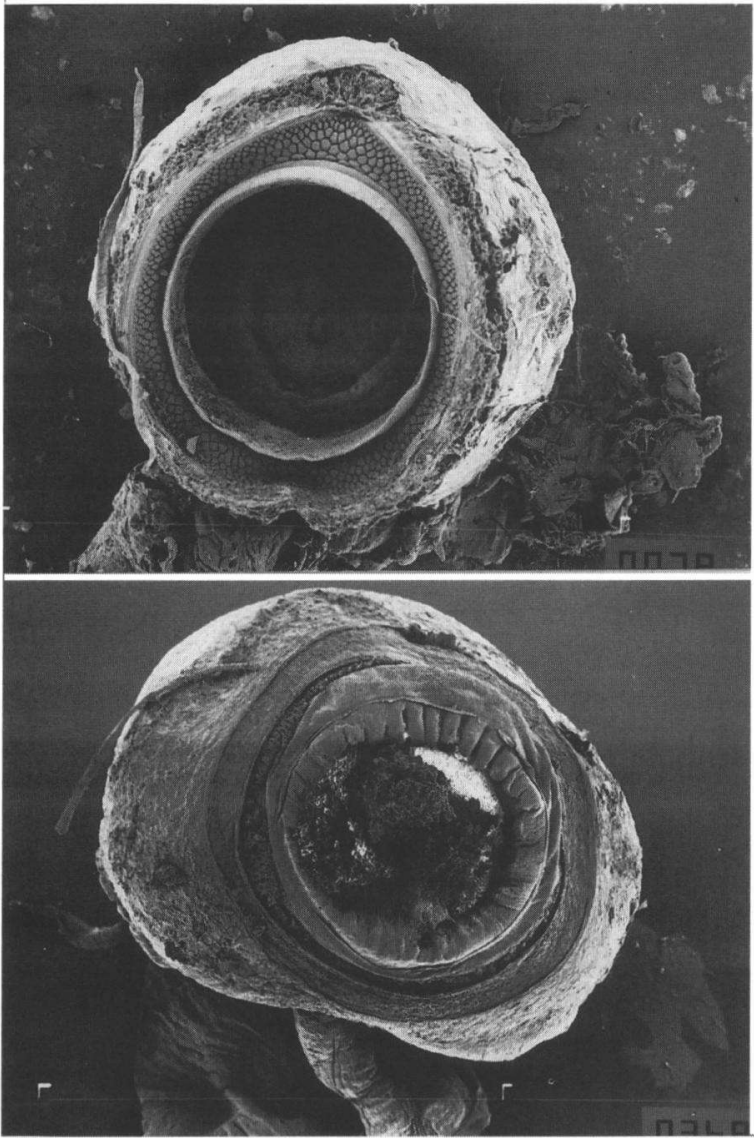
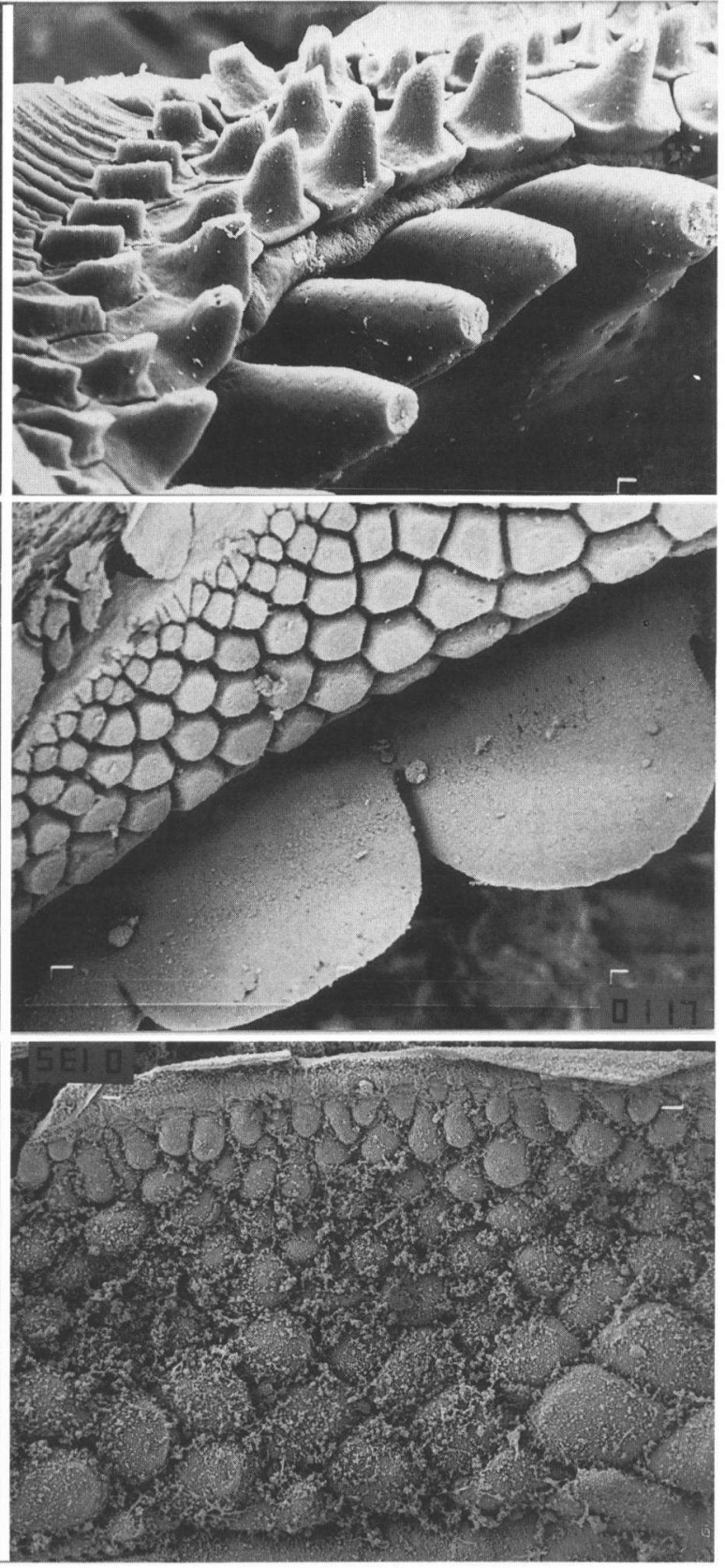

Figs. 2-7. Arm suckers: 2, Mastigoteuthis agassizi, proximal sucker, arm IV ( $80 \times)$; $3, M$. agassizi, detail of the pegs, teeth and adjacent denticles of the distal margin $(800 \times) ; 4$, Idioteuthis magna, proximal sucker, arm II $(80 \times) ; 5,1$. magna, close-up of the teeth and polygonal processes of the distal margin $(400 \times) ; 6, I$. cordiformis, medial sucker, arm II $(60 \times) ; 7, I$. cordiformis, detail of the polygonal processes of the proximal margin $(800 \times)$.

morphology may change in the same individual from arm to arm, even from row to row, especially in large specimens. Nevertheless, the general patterns of the polygonal processes remain constant. 


\section{Ultrastructure of tentacular suckers}

The tentacular suckers show a morphological pattern closely related to that of arm suckers. The tentacular club of the Mastigoteuthidae shows 12 to 30 or more rows of suckers around the stalk, with the aboral side remaining free of suckers. The suckers are characterized by their minute size. Morphologically they are also divided into two types: (1) elongate sucker surface, sharp pegs, dentated infundibular rings; (2) round sucker surface, smooth infundibular ring.

\section{Tentacular sucker type 1}

(Figs. 8-10)

This type of sucker is disto-proximally elongated, with two to three types of pegs in the genus Mastigoteuthis (Figs. 8, 9).

Acetabulum. - The outline is elongate. The opening is moderate. The acetabulum is extremely reduced to a transparent membrane, and is attached to the tentacle by a very thin and elastic stalk.

Infundibular ring. - The teeth only appear in the distal margin and are square in shape, their number ranging from 3 to 5 . The infundibular chamber is as big as the papillated ring, but in large specimens the infundibular chamber is elongate and larger than the papillated ring (Fig. 9).

Papillated ring. - This ring consists of three subrings. In juvenile specimens (50 to $70 \mathrm{~mm} \mathrm{ML}$ ) or in the distal suckers of mature specimens $(150 \mathrm{~mm}$ $\mathrm{ML}$ ), the arrangement of the polygonal rings is nearly radial, without apparent differentiation between the shape of the pegs in each ring, except for the size. The internal ring has larger, slightly ovate pegs, while the intermediate ring has smaller, circular ones, and the external ring has still smaller pegs. Distal suckers in the process of formation have elongate pegs (Figs. 8, 9) in the external ring.

The pegs in mature specimens are better developed and differ clearly depending on the ring, particularly in the suckers on the middle part of the tentacular stalk. The outer surface of the rim is enlarged, especially at the lateral margins (Fig. 9). The external ring has truncate and round pegs. The 3 to 4 pegs at the distalmost corner of the notched ring are modified, allowing the suckers to make the "close-open" movement (the "close-open" movement is a hypothesis based on observations of preserved suckers and deduced from the specific morphology of the pegs in the distal margin) (Figs. 9, 10).

The intermediate ring has conical and slightly wedge-shaped pegs that are larger than those of the external ring. In its distal margin, 3 to 4 very sharp pegs of about the same size are present. On both lateral margins of the internal ring, 2 to 3 irregular and enlarged wedge-shaped pegs are present and they project into the aperture of the sucker. In the proximal margin, 2 to 3 plate-like polygonal processes can be observed (Fig. 9).

Remarks. - It was observed in large specimens of Mastigoteuthis ( $\geq 160 \mathrm{~mm} \mathrm{ML}$ ) that the pegs are longer and sharper, but the size of the sucker is not larger than in juvenile specimens. This is especially evident in $M$. famelica (Berry, 1913).

\section{Tentacular sucker type 2}

(Figs. 11-13)

The tentacular suckers in Idioteuthis are spherical in shape, and nearly all the pegs are of a similar type. The sucker surface looks circular in the proximal-distal plane, and the arrangement of the pegs is nearly radial.

Acetabulum. - The outline is spherical, and its opening small. The stalk is thin and moderate to long. In large specimens of 1 . cordiformis (> 300 $\mathrm{mm} \mathrm{ML)} \mathrm{the} \mathrm{suckers} \mathrm{in} \mathrm{the} \mathrm{proximal} \mathrm{part} \mathrm{of} \mathrm{the} \mathrm{ten-}$ tacles are as big as the distal suckers of arm I. On the other hand, for I. magna it is possible to observe the sucker's face in detail only by using TEM or SEM.

Infundibular ring. - The ring has no teeth in $I$. magna (Fig. 12), but in I. cordiformis a type of 


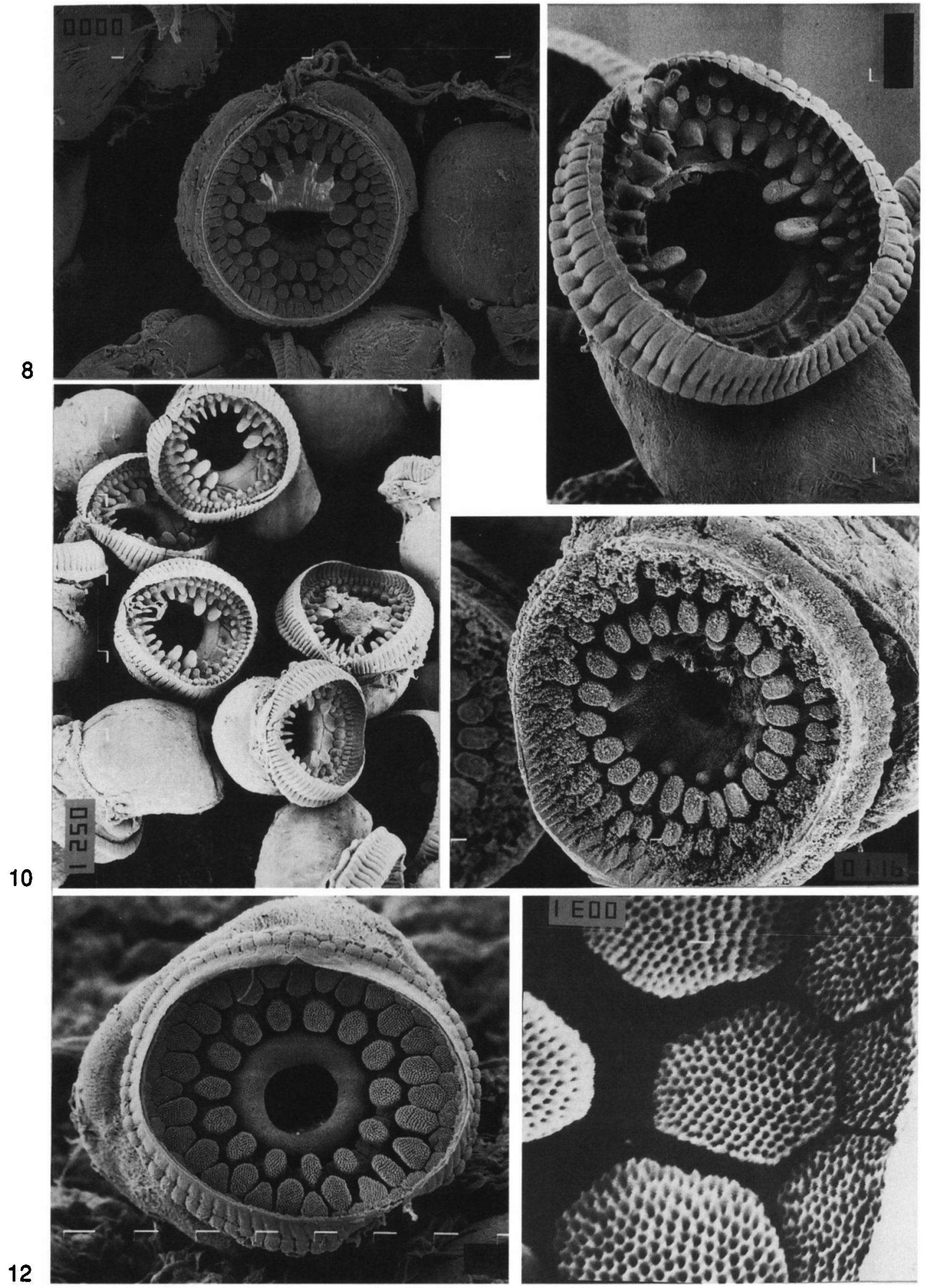

9

Figs. 8-13. Tentacular suckers: 8, Mastigoteuthis glaukopis $(400 \times) ; 9$, M. famelica $(800 \times) ; 10, M$. famelica, aspect showing the hypothetic "close-open" movement of the papillated ring $(80 \times)$; 11, Idioteuthis cordiformis, distal sucker $(160 \times) ; 12, I$. magna $(1200 \times)$; 13, I. magna, detail of the pores of the pegs $(6000 \times)$. 
blunt teeth are present along the margins (Fig. 11). A short neck between the ring and the chamber is evident. The infundibular chamber is spherical.

Papillated ring. - Three sub-rings are also present. The pegs of the external ring are very small and closely attached to the intermediate ring, giving the appearance that there are only two sub-rings (Figs. $11,12)$. The internal ring of $I$. cordiformis has larger and more ovate pegs than the intermediate ring. The internal ring of $I$. magna has fewer pegs, which are nearly circular in shape, while the intermediate ring has larger pegs that are clearly polygonal in shape (Figs. 12, 13).

Remarks. - In large specimens of $I$. cordiformis ( $>300 \mathrm{~mm} \mathrm{ML}$ ), the suckers increase in size, in the middle part of the tentacle in particular.

\section{Ultrastructure of cushions}

(Figs. 14-19)

Cushions are cushion-like structures present in arm and tentacular suckers, characterized by their globular shape and softness. They are formed mainly in the internal walls of the veil or the infundibular chamber. Morphologically, they are very variable, their size and number varying in every single sucker. However, two types of cushions are recognizable: (1) the spongy-type, usually soft, commonly present in tentacular suckers; and (2) the hornytype, usually present in arm suckers.

The cushion of tentacular suckers is formed from the internal walls of the infundibular ring. Its size depends on the species and size of the specimen. In Mastigoteuthis, cushions are present mainly in the suckers of the middle part of the tentacle. The cushion usually is present in the proximal margin. The appearance of the sucker cushion differs from sucker to sucker (Figs. 14, 15).

In Idioteuthis, cushions are only present in I. cordiformis, in which the cushion grows first internally around the infundibular ring (Figs. 17, 18), detaching the papillated ring or the ring being covered by the cushion, so that just the infundibular chamber and the cushion remain (Fig. 16). Occasionally, the cushion grows out from the infundibulum, giving it the appearance of a boxing glove (Fig. 19).

\section{Discussion}

\section{Sucker terminology}

The indiscrimate use of terms in the naming of sucker components, especially when SEM is used, leads to misunderstandings or failures in the descriptions of sucker morphology in taxonomic contributions. The purpose of introducing this revised terminology is to provide standardized descriptions of the morphology of suckers. First, this is necessary in the family Mastigoteuthidae and in taxa which have a closely related sucker morphology, as well as in paralarval specimens of all groups of squids, in order to understand their ontogenetic changes and phylogenetic relationships. Second, it is expected that this terminology may help in the description of all cephalopod suckers.

Identification by suckers and its systematic value

The use of sucker morphology for species discrimination has occurred in very limited cases with regard to small suckers, this probably being due to the need of re-evaluation of sucker morphology and terminology. For example, Young (1972) defined the species Mastigoteuthis pyrodes by the structure of its tentacular suckers. Young was the first who evaluated the morphology of mastigoteuthid tentacular suckers, although considering the pegs as teeth. Nesis (1977) believed the use of tentacular sucker size to be the only way to separate mastigoteuthid species, based on Young's (1972) observations. It is stated here that the morphology of the papillated ring makes the identification of paralarvae as well as adults more reliable.

Additional SEM studies in which tentacular suckers were described in order to define species are those by Okutani \& Horita (1987) on two species of Euprymna, and by Okutani \& Takayama (1991) on two species of Sepiola from Japanese waters. These examples support the idea proposed here that the 
14
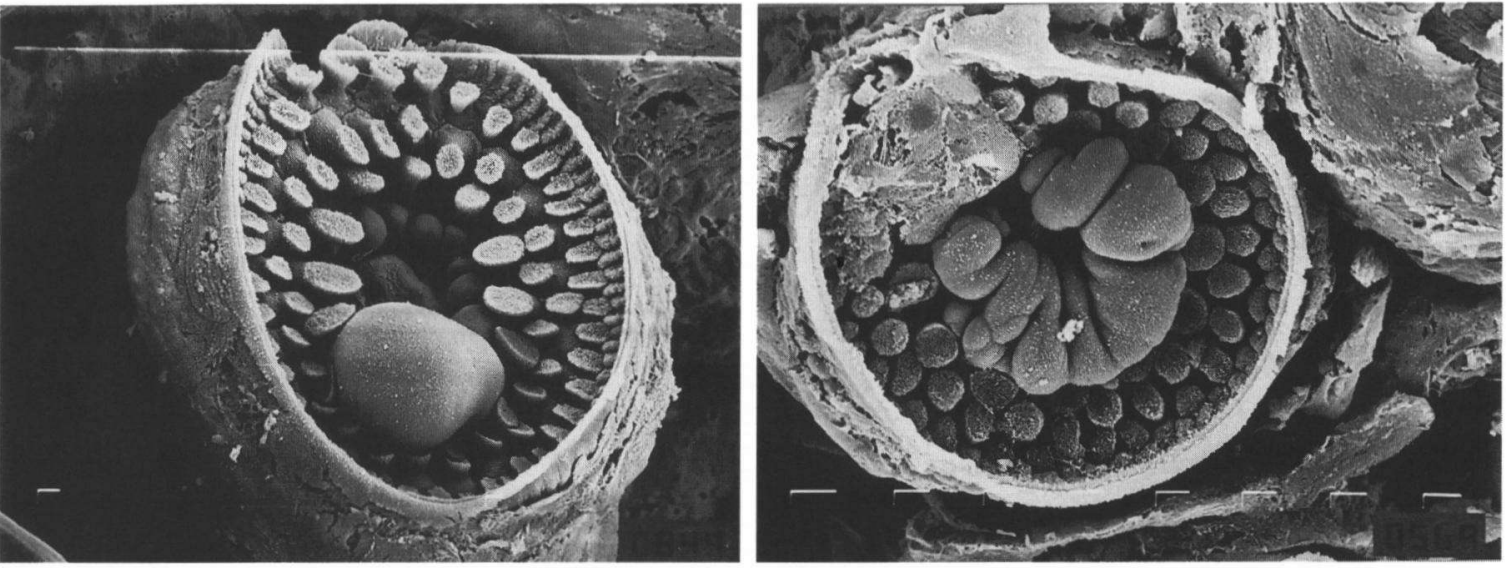

16
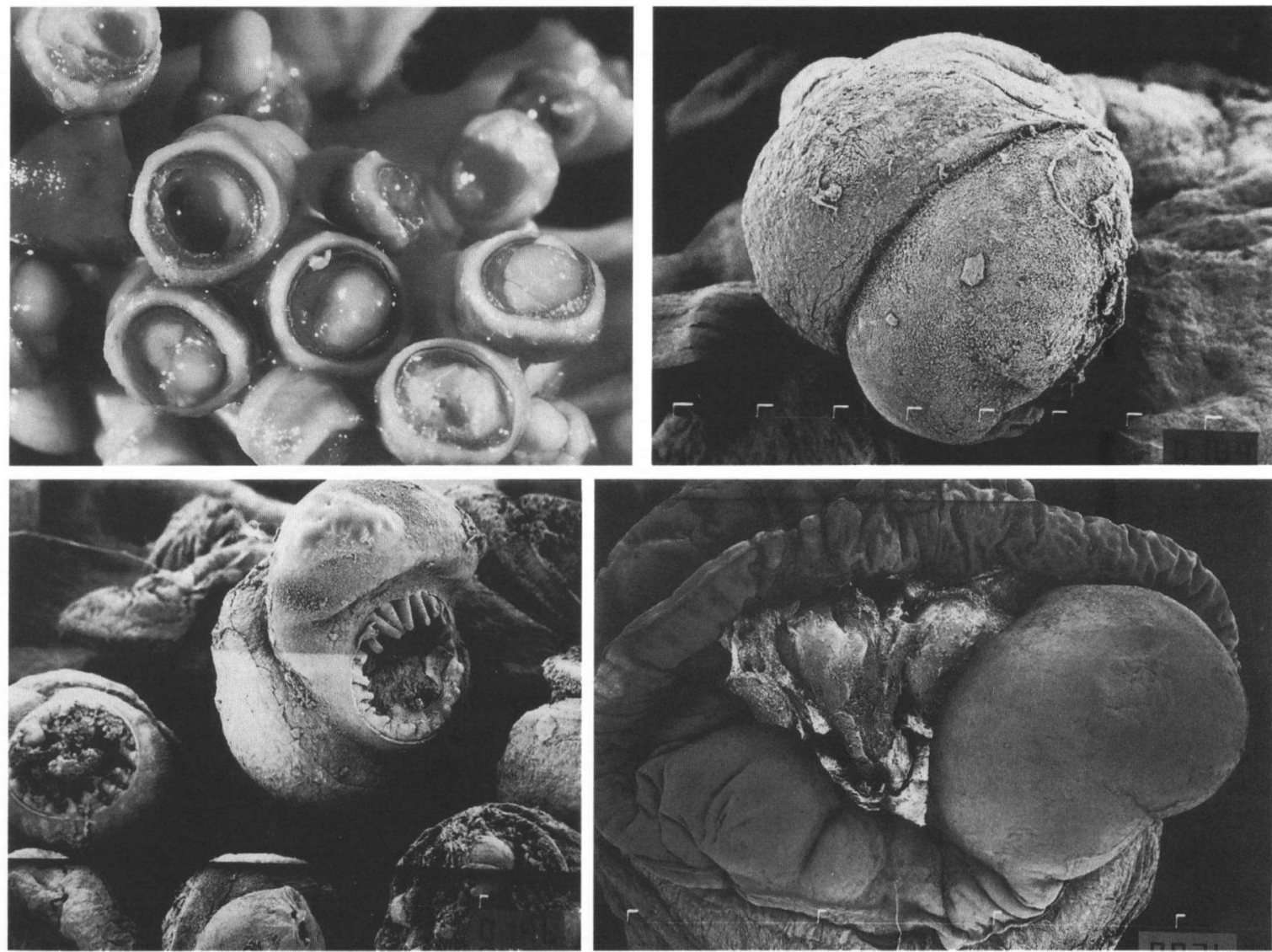

Figs. 14-19. Spongy-type cushions: 14, Mastigoteuthis agassizi, on tentacular sucker $(600 \times) ; 15, M$. famelica, on tentacular sucker $(1500 \times) ; 16$, Idioteuthis cordiformis, general view of the cushions in proximal tentacular suckers $(16 \times) ; 17, I$. cordiformis, sucker modified by the cushion $(120 \times) ; 18, I$. cordiformis, variation in the development of the cushion in tentacular suckers $(80 \times)$; $19, I$. cordiformis, the most enlarged sucker, showing the probable last step in the development of cushions in this species $(28 \times)$. 
systematic value of the sucker surface, specifically the papillated ring which is the main component in small suckers, is important not only for mastigoteuthid species but also for other cephalopod taxa with small suckers such as Sepiola and Euprymna.

In Northwest Pacific material of Mastigoteuthidae, the subgenera Mastigoteuthis, Echinoteuthis, Idioteuthis, and Magnoteuthis could be distinguished by their sucker components (SalcedoVargas, 1993; Salcedo-Vargas \& Okutani, 1994). Emphasis has been placed on the papillated ring as a new taxonomic character for the taxa studied, because in small-sized suckers the infundibular ring gets secondary taxonomic value and the papillated ring takes its place as the main component of the sucker surface. This re-evaluation of sucker components is likewise important for the reconstruction of phylogenetic relationships, and can be helpful in the process of identification of undescribed sucker components in other cephalopod taxa.

\section{Cushion re-evaluation}

Structures like rings, teeth, and other subcomponents of suckers are of extremely variable biochemical composition. The re-evaluation of the cushioned suckers in the present paper suggests that there is a transformation of the horny ring protein structure into a different protein. This demands a revision of the taxonomic study of suckers, primarily in the Mastigoteuthidae.

In order to evaluate the cushions as an important subcomponent of sucker morphology, it is necessary to understand that suckers are structures in constant transformation, such as the well-known transformation from ordinary suckers into hooks, which is currently an accepted phenomenon. Many families, genera, or species have been described based on the shape, size and number of hooks. Engeser \& Clarke (1988) summarized the morphology and evolution of fossil and recent hooks, indicating the importance of their chemical composition. However, nothing has been documented about the cushions.

The cushions are considered here as another kind of transformation from ordinary suckers, in addition to teeth and hooks. This particular structure was originally reported by Joubin (1895) with regard to the family Chiroteuthidae. Pfeffer (1900) considered cushions to be an unusual condition. Chun (1910) attempted to explain cushion formation by examining the type specimen of Chiroteuthis picteti (Joubin, 1894) and described the formation of hump-shaped thickenings inside the acetabulum. Similar formations were observed in other suckers by Chun (1910), who concluded that it is the last stage of a series of probably pathological modifications. The fusion of the swellings and the denticles led Chun to the conclusion that this is a rare, abnormal dentition.

Chun (1910) also noted closely related structures in the suckers of $M$. cordiformis Chun, 1908 (now Idioteuthis). Later, in the description of I. latipinna (= I. cordiformis), Sasaki (1916) defined similar structures as "lumps of irregular shape". Sasaki $(1916,1929)$ also thought that cushions were pathological malformations.

Detailed examination and cross section views (Fig. 1e) of cushions in suckers of Mastigoteuthidae from the Northwest Pacific shows that the spongy cushion material is different from the horny material. Further investigations of their respective chemical compositions are needed. Biologically, the cushions should not be considered as pathological formations, but rather as adaptations, probably to deep-sea life.

The reason why such a formation has not been discussed in depth earlier, and why cushions have never been subjected to taxonomic/phylogenetic character analysis may be attributed to the following causes: (1) infrequent opportunity to observe specimens with cushions, (2) low accessibility of complete tentacles of adult specimens, (3) frequent loss of sucker rings in many specimens, (4) irregular patterns in cushion formation, and (5) presence of remnants of teeth in spite of the complete formation of cushions.

The presence of cushions is not exclusive to this particular family, as they were also observed in Chiroteuthidae (Joubin, 1895), Joubiniteuthidae, and Grimalditeuthidae, and in more distantlyrelated families such as Bathyteuthidae, Lepidoteuthidae, Pholidoteuthidae and Octopoteuthidae (personal observations).

The cushions cannot yet be classified or used for 
systematic purposes, since they do not show a consistent pattern of formation. For the time being they can be considered simply as a character useful for identifying lifestyle and age.

At the moment, the presence of cushions as a structure derived from the internal walls of suckers with well-developed veils or infundibular chambers, suggests that this is a common feature in sexually mature bathypelagic cephalopods.

\section{Acknowledgements}

I am grateful to Dr. Takashi Okutani of the Tokyo University of Fisheries for his supervision of my doctoral dissertation and for his corrections in the present paper, and to Captains and crews of the R/V's "Kaiyo-Maru" and "Kotaka-Maru", as well as scientists on board for their great efforts in sampling the biological specimens on which this study was based. To Dr. Hiroshi Saito (National Science Museum, Tokyo) for his assistance and helpful advice in the use of the Scanning Electron Microscope. To Prof. Dr. S. van der Spoel of the University of Amsterdam for his comments on this paper and for the opportunity to study in his laboratory. Fruitful comments by anonymous reviewers are also acknowledged.

\section{Literature cited}

Chun, C., 1910. Die Cephalopoden. Wiss. Ergebn. dt. TiefseeExped. "Valdivia", 18 (1, Oegopsida): 1-401, pls. I-II, I-LXI [English translation, Israel Program for Scientific Translations, vol. 18 (1975): 1-552, atlas of 95 plates].

Dilly, P.N., M. Nixon \& J.Z. Young, 1977. Mastigoteuthis - the whip-lash squid. J. Zool., Lond., 181(4): 527-559.

Engeser, T.S. \& M.R. Clarke, 1988. Cephalopod hooks, both recent and fossil. In: M.R. Clarke \& E.R. Trueman (eds.), The Mollusca, vol. 12. Paleontology and neontology of cephalopods: 133-151 (Academic Press, San Diego).

Haas, W., 1989. Suckers and arm hooks in Coleoidea (Cephalopoda, Mollusca) and their bearing for phylogenetic syste- matics. Abh. naturwiss. Ver. Hamburg., (NF) 28: 165-185. Joubin, L., 1895. Contribution à l'étude des Céphalopodes de l'Atlantique Nord. Résult. Camp. scient. Prince Albert I, 9: $1-63$, pls. I-IV.

Kristensen, Th.K., 1977. Scanning electron microscopy of hook development in Gonatus fabricii (Lichtenstein, 1818) (Mollusca: Cephalopoda). Vidensk. Meddr. dansk naturh. Foren., 140: $111-116$.

Naef, A., 1921-1923. Cephalopoda. Fauna Flora Golfo Napoli., 35(1): 1-863; (2): 1-357 (translated from the German; Israel Program for Scientific Translations, Jerusalem, 1972).

Nesis, K.N., 1977. Mastigoteuthis psychrophila sp. n. (Cephalopoda, Mastigoteuthidae) from the Southern Oceans. Zool. Zh., 56(6): 835-842.

Nixon, M. \& P.N. Dilly, 1977. Sucker surfaces and prey capture. In: M. Nixon \& J.B. Messenger (eds.), Biology of cephalopods. Symp. zool. Soc. London, 38: 447-511 (Academic Press, London/New York).

Okutani, T. \& E. Horita, 1987. Identity of Euprymna berryi Sasaki, 1929 (Cephalopoda, Sepiolidae). Venus, Jap. J. Malac., 46(2): 91-107.

Okutani, T. \& K. Takayama, 1991. The Sepiola parva and S. birostrata problem. Bull. mar. Sci., 49(1-2): 666 (Abstract).

Pfeffer, G., 1900. Synopsis der oegopsiden Cephalopoden. Mitt. naturh. Mus. Hamb., 17: 147-198.

Salcedo-Vargas, M.A., 1993. Revision of the squid family Mastigoteuthidae (Mollusca: Cephalopoda) from the Northwest Pacific: 1-264 (Doctoral dissertation, Tokyo University of Fisheries).

Salcedo-Vargas, M.A. \& T. Okutani, 1994. New classification of the squid family Mastigoteuthidae (Cephalopoda: Oegopsida). Venus, Jap. J. Malac., 53(2): 119-128.

Sasaki, M., 1916. Notes on oegopsid cephalopods found in Japan. Annotationes zool. jap., 9(2): 89-120, pl. III.

Sasaki, M., 1929. A monograph of the dibranchiate cephalopods of the Japanese and adjacent waters. J. Coll. Agric. Hokkaido Imp. Univ., 20 (Suppl.): 1-357, pls. I-XXX.

Young, R.E., 1972. The systematics and areal distribution of pelagic cephalopods from the seas off southern California. Smithson. Contrib. Zool., 97: 1-iii, 1-159.

First draft received 14 April 1994

Revised: 8 May 1995 